\title{
Graphical modeling with the chorematic method. A case study on Saudi Arabia.
}

\author{
Mohsen DHIEB * \\ University of Sfax-Faculty of Arts and Humanities - Department of Geography-Laboratory SYFACTE-GEOMAGE \\ Mohsendhieb2003@yahoo.fr
}

* Corresponding author: Mohsen DHIEB

Keywords: Chorem - Chorematics - Spatial Modeling - Kingdom of Saudi Arabia

\begin{abstract}
:
In geographical research, the chorematic method (from the French word chorème of French geographer R. Brunet, 1983) has been presented as a meaningful graphical modeling method of geographical spaces. In its author's thought, it is meant to resume the specific characters and overall design of one given space whatever its configuration, its characteristics, and its extent by using very simplified graphical shapes, figures, colors and textures. The graphical modeling by chorems is sensed to express the profound inner space structures, patterns and relationships of spaces.

This graphic method and its applications were applied mostly in western countries and especially in France and Latin countries to portray various spaces and various phenomena. They were not well known in the Third World countries according to the literature. Yet they proved certain learning qualities and high ability to synthesize space.

One goal of the research is to implement, discuss and evaluate a case application of chorems on the Kingdom of Saudi Arabia. Another goal is to measure to what extent this method may be useful to portray and understand spatial structures and to what extent automation of its steps may help.

Another goal is to try to state a set of rules and guidelines to realize easily series of chorems that apply to one space. The idea behind is to try to make the design of chorems more systematic and not depending on authors subjective point of view and to evaluate if this challenge can be realized The examples studied are derived from the geography of the Kingdom of Saudi Arabia, thematic data are about its natural and human resources, the spatial mobility of its human components and their evolution over time.
\end{abstract}

The author concludes that Chorems are figures that may yield useful ideas and guidelines for featuring the development of one economy with regards to its spatial planning policy, i.e., in the case of Saudi Arabia, the future vision of the Kingdom 2030. 